\title{
Positive end expiratory pressure test can predict fluid responsiveness in patients with septic shock
}

Fot E.V., Ilyina Y. Y., Sokolova M. M., Ushakov A. A., Izotova N.N., Smetkin A.A., Kuzkov V.V., Kirov M.Y.

Department of Anesthesiology and Intensive Care, Northern State Medical University, Arkhangelsk, Russian Federation

Background and goals: The transient increase of positive end expiratory pressure (PEEP test) is a promising bedside approach to assess the response of fluid resuscitation, however requiring further validation in different clinical situations. The goal of our study was to assess whether PEEP test predicts fluid responsiveness in patients with septic shock.

Methods: Seventeen adult patients with septic shock were enrolled into an ongoing prospective observational study. All the patients received vasopressor support, pressure-controlled ventilation with tidal volume of $8 \mathrm{~mL} / \mathrm{kg}$ and standardised PEEP $8 \mathrm{~cm} \mathrm{H}_{2} \mathrm{O}$, and sedation with continuous infusion of propofol. The PEEP test consisted of a transient increase of PEEP from 8 to $20 \mathrm{~cm} \mathrm{H}_{2} \mathrm{O}$ during $5 \mathrm{~min}$. Thereafter, all patients received fluid challenge $(7 \mathrm{ml} / \mathrm{kg}$ of crystalloids during $10 \mathrm{~min}$ ). Systolic arterial pressure (SAP), mean arterial pressure (MAP), pulse pressure variations (PPV), thermodilution cardiac index (CI), and CI determined with pulse contour analysis (PCCI) were measured using $\mathrm{PiCCO}_{2}$ monitor (Pulsion Medical Systems, Germany) before, during, and after PEEP test, as well as after the fluid load. The patients with an increase in CI by $\geq 15 \%$ after fluid challenge were defined as fluid responders. The statistical analysis was performed using Mann-Whitney U-test, Wilcoxon test and ROC analysis. Data are presented as median (25th-75th percentiles).

Results: The baseline characteristics did not differ between the groups (Table 1), although there was a trend for increased extravascular lung water in non-responders. In both responders and non-responders, PEEP test resulted in a significant decrease in SAP within the first 30 seconds only $(\mathrm{p}<0.05)$, while in responders the decrement of SAP persisted until the end of the test. To 3 min after the start of PEEP test, SAP reduced by 18 (4-24) mm $\mathrm{Hg}$ in responders, but increased by 11 (-715) $\mathrm{mm} \mathrm{Hg}$ in non-responders (Figure 1).

Figure 2. ROC-curve for decrease in systolic arterial pressure $>14 \mathrm{~mm} \mathrm{Hg}$ at 3 min during PEEP test and fluid responsiveness.

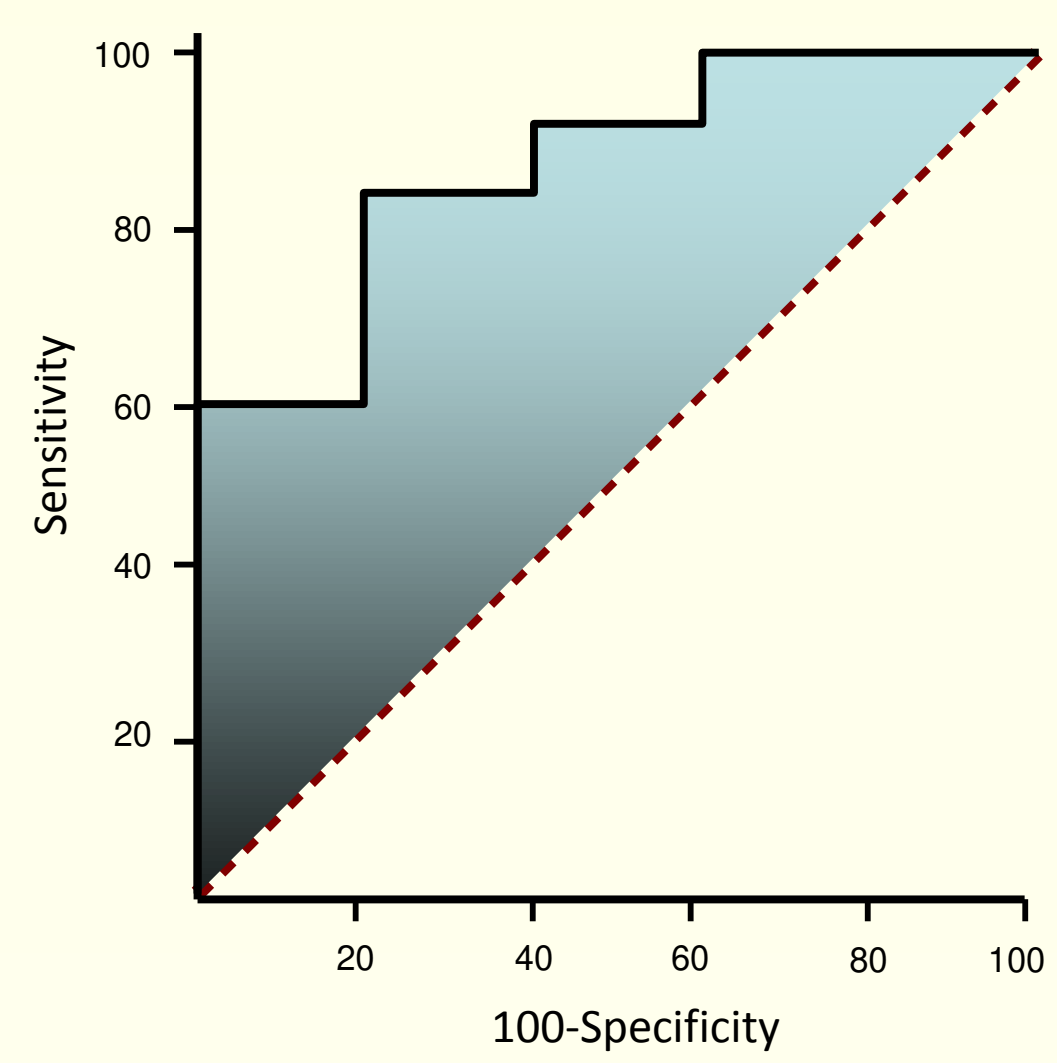

The decrease in SAP exceeding $14 \mathrm{~mm} \mathrm{Hg}$ identified fluid responders with area under the curve (AUC) 0.85 , sensitivity $58 \%$ and specificity $100 \%$ ( $\mathrm{p}=0.03$ ) (Figure 2). During PEEP test, PPV, MAP, and PCCI decreased without significant differences between the groups. ROC analysis revealed that the decrease in $\mathrm{CI} \geq 0.5 \mathrm{~L} / \mathrm{min} / \mathrm{m}^{2}$ from the first to the fifth minute of the test predicted responders to fluid load with AUC 0.89 , sensitivity $80 \%$ and specificity $100 \%(p=0.015$, Figure 3$)$.

Conclusion: In septic shock, the PEEP test can be used to predict fluid responsiveness but requires thorough hemodynamic monitoring.

Table 1. The main baseline characteristics of the patients

\begin{tabular}{l|c|c|c}
\hline Characteristic & Responders & Non-responders & $p$ \\
\hline Age, years & $60(45-76)$ & $47(39-56)$ & 0.1 \\
\hline $\mathrm{CI}, \mathrm{L} / \mathrm{min} / \mathrm{m}^{2}$ & $3.02(2.2-3.7)$ & $3.7(2.6-5.5)$ & 0.28 \\
\hline GEDVI, $\mathrm{mL} / \mathrm{m}^{2}$ & $631(580-656)$ & $809(514-860)$ & 0.23 \\
\hline EVLWI, $\mathrm{mL} / \mathrm{kg}$ & $8(6-11)$ & $15(8-20)$ & 0.1 \\
\hline Lactate, $\mathrm{mmol} / \mathrm{L}$ & $4.3(2.2-7.1)$ & $4.5(1.05-4.7)$ & 0.3 \\
\hline
\end{tabular}

CI, cardiac index; CEDVI - global end-diastolic volume index; EVLWI, extravascular lung water index.

Figure 1. Changes in systolic arterial pressure (SAP) at 3 min of the PEEP test

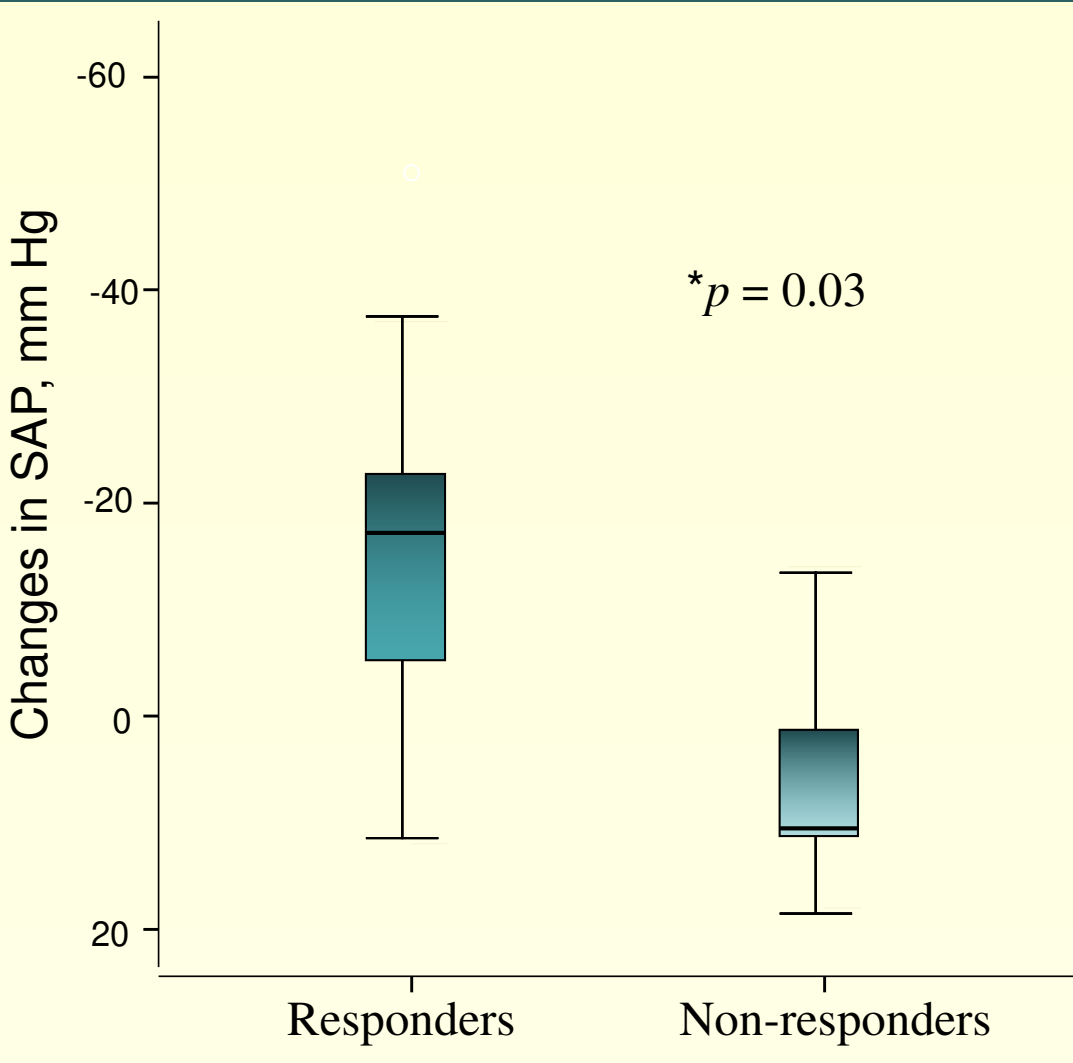

Figure 3. ROC-curve for decrease in cardiac index $\geq 0.5 \mathrm{~L} / \mathrm{min} / \mathrm{m}^{2}$ from minutes 1 to 5 of the PEEP test and fluid responsiveness.

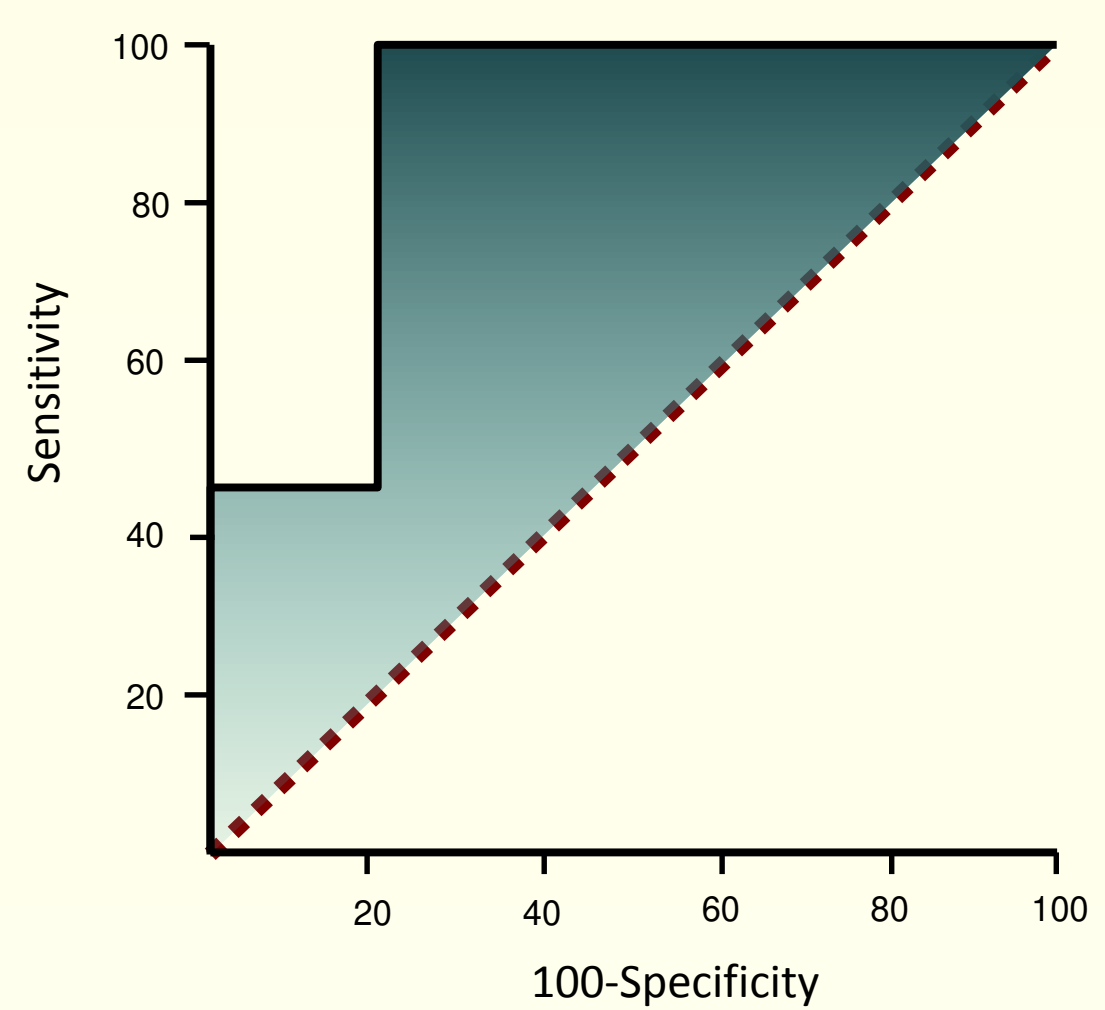

Copyright @ 2018 Evgenia V Fot, e-mail: ev_fot@mail.ru 